\title{
PREVENTIVE MEDICINE ON THE FARM
}

$A^{1}$

$\mathrm{T}$ the Liverpool meeting of the British Association, Section M (Agriculture) devoted the morning of September 7 to a discussion on "Preventive Medicine among Farm Livestock" with Dr. John Hammond (Cambridge) in the chair. The prominence of animal health in the programme of this section illustrated both the close association between agriculture and veterinary science and the need for increasing animal production.

In his introductory remarks, Prof. E. G. White (University of Liverpool) defined preventive medicine as "keeping animals healthy by preventing disease" and illustrated some of the ways in which farm livestock can be protected against diseases, whether introduced at intervals from abroad (foot-and-mouth disease, anthrax, fowl pest) or established within Great Britain. Prevention, said Prof. White, is not only better than cure, it is also cheaper, which is an important advantage to the farmer.

A number of serious animal plagues were eradicated from Great Britain by restriction of the importation of animals and raw animal products, slaughter of affected animals and in-contacts, and sanitary measures. These methods are still used for some of the diseases that enter Britain from time to time, such as the serious and widespread outbreaks of foot-and-mouth disease during 1951-52 which were due to infection from Europe, possibly transmitted by migrating birds. In recent years two more notifiable diseases, parasitic mange of horses and sheep scab, have been eradicated. Protection of stock with vaccines and other biological agents is of particular value where the causal agents of disease live in the soil, as with a number of sheep diseases. Vaccination is also of great value for contagious abortion in cattle and swine fever. With internal parasites, such as liver flukes and nematodes, it may be impossible entirely to prevent animals becoming infected. The method of control is to limit the level of infestation by proper grazing practice, to control disease by strategic dosing with anthelmintics and to provide a good standard of nutrition in order to increase the host's resistance to the parasites.

Poisoning among farm animals, particularly lead poisoning in cattle caused by licking painted wood or metal objects, can usually be prevented. Fluorosis has been found to be a serious problem in the neigh. bourhood of certain types of industrial plant : brick works, aluminium works and some types of steel works have been incriminated. Piped main water is a valuable weapon of preventive medicine on the farm; too many farms still have to rely on wells and ponds for their water supply. This makes clean milk production and disinfection difficult, and favours the spread of disease.

The losses due to disease in livestock are difficult to assess because there are no accurate figures for disease incidence, except for the notifiable diseases. Losses certainly amount to many millions of pounds each year. Much of this loss can be avoided. Damage to hides due to the larvæ of the warble fly, for example, caused a loss of nearly half a million pounds to the Ministry of Food in 1952 : the fly could be eradicated from many areas if cattle were regularly dressed with the statutory preparations.
The disease picture is continually changing. When new methods of control become effective against some diseases, others are brought to light. Thus control of trichomoniasis revealed Vibrio foetus as a cause of infertility in cattle. The use of antibiotics for mastitis, vaccination for contagious abortion and several sheep diseases, and anthelmintics and insecticides for internal parasites has greatly reduced the losses from these diseases in recent years, and more attention can now be paid to the diseases that remain. Preventive medicine embraces not only those diseases that are caused by infective agents but also covers a much wider field, including the prevention of nutritional and metabolic diseases and poisoning and the avoidance of methods of breeding, housing or management that favour disease. With better control of infectious diseases there is an opportunity to devote more attention to diseases caused by factors other than infective agents.

Prof. White concluded by remarking that although the cure of existing disease and the relief of suffering are very necessary, the first duty of medicine is to prevent disease. But whereas the successes of curative medicine are easily measured, the real triumphs of preventive medicine are not, for they are the things that do not happen.

The contribution of the State to disease prevention and control, through the full-time staff of the Animal Health Division and the panel of part-time veterinary practitioners, was dealt with by Mr. J. N. Ritchie (chief veterinary officer, Ministry of Agriculture and Fisheries).

Mr. Ritchie dealt first with the notifiable diseases which owners are required by law to report to the police when they are suspected. Some of these diseases (cattle plague, bovine pleuropneumonia, sheep pox, glanders, epizootic lymphangitis and rabies) have been eradicated by slaughter of affected and in-contact animals, control of importation and movement, and sanitary measures. Modern sheep dips containing 'Gammexane' have helped to eradicate sheep scab because they necessitate only a single dipping instead of double dipping. There has been no sheep scab in Scotland for twelve years and none in England and Wales since 1951.

A wide variety of regulations exist to control the importation of animals, animal products, and goods that may convey infection mechanically from abroad; but since we must still depend to some extent on imported animal feeding-stuffs and fertilizers and on imported meat. a certain amount of risk must be accepted. Outbreaks of anthrax usually arise from imported feeding-stuffs and fertilizers, and during 1952-53 there was a particularly high incidence of the disease, especially among pigs. Three-quarters of all primary outbreaks of foot-and-mouth disease are probably caused by infected swill containing the virus in the form of waste meat from imported chilled carcases. The separation of swill from livestock until it has been boiled for one hour is a valuable method of preventing this disease, as well as swine fever and fowl pest. Swine fever is perpetuated by movements of pigs through markets and dealers' premises, and its control is fairly rapid when movement restrictions are imposed. Greater 
use of vaccination would help to reduce the incidence of the disease. Fowl pest was re-introduced into Britain in 1947 with imported poultry carcases, after fourteen years freedom from infection. Control is by the slaughter of infected and in-contact birds but is hampered by the occurrence in recent years of a sub-acute form of the disease which is difficult for the farmer to detect but is very contagious.

Perhaps the greatest achievement of preventive veterinary medicine of recent years is the scheme to eradicate tuberculosis from cattle by the Attested Herds Scheme and the establishment of free-testing, eradication and attested areas. By the end of March 1953 almost four million cattle, representing $41 \cdot 4$ per cent of the total stock, were in attested herds. Attested areas containing some 700,000 cattle have been established in south-west Scotland, south-west Wales, Shetland and the Scilly Isles. Adjacent to the areas in Scotland and Wales are free-testing areas containing another million cattle which will soon more than double the cattle population in attested areas. Abortion due to brucellosis has been well controlled by vaccination, and that due to trichomoniasis has responded to treatment of infected cows and the use of artificial insemination.

In addition to the field-work involved in preventing and controlling disease, the Animal Health Division has a laboratory diagnostic and research service which operates from two main laboratories at Weybridge and Lasswade and from the divisional diagnostic laboratories which exist in most counties and the Veterinary Investigation Centres.

Dr. E. L. Taylor (Weybridge) introduced the subject of parasitic diseases by stating that half of the living creation is parasitic on the other half, and that the species of parasite are more numerous than the species of host on which they live. Dr. Taylor illustrated the importance of parasitic disease on animal production by discussing the losses caused by the parasitic nematodes. He presented a picture of parasitism of stock in four periods in history. In the first period, a mythical Garden of Eden, parasite and sheep lived happily together because there was plenty of room for animals to graze and so the intake of infective stages of the parasites was small. Sheep were able to maintain their worm population at a level which was compatible with health. In the second period, that of trial and error, farmers began to domesticate animals, to enrich the soil and to fence the land. Parasites flourished and losses among farm stock were severe. By a process of trial and error farmers found ways of reducing their losses. There followed the present age, the age of reason, during which knowledge of parasites and their lifehistories enables man to use anthelmintics and methods of pasture management which help to reduce losses. An experiment at Weybridge with twin lambs, one of each being kept worm-free and the other infected with a moderate number of worms, showed that by the end of the year the average weight of the infested lambs was some $30 \mathrm{lb}$. less than that of their worm-free twins. This difference occurred in spite of anthelmintic treatment. Since worms are ubiquitous where sheep are kept, this difference between optimal gain and 'normal' gain is very considerable, and Dr. Taylor calculated that even if the difference amounted to only $10 \mathrm{lb}$. per lamb it would mean a loss of some 18,000 tons of meat a year.

The fourth age, the age of eradication, has hitherto seemed to be unattainable; but there is now some hope that, at least for some species of worm, it may well be reached. Experiments by Dr. Spedding at the Grassland Research Station with sheep on arable land have shown that the use of phenothiazine, together with a folding system, can enable sheep to be kept free from worms altogether. Although such a procedure may not for a long time become practicable farming practice, it nevertheless marks a beginning, and with the development of better parasiticides may well open up a method which could enable animal production to be raised to a level far higher than had been thought possible.

The symposium ended with a contribution from Mr. J. O. L. King (University of Liverpool) on the influence of animal husbandry on disease. Domesticated livestock of to-day, Mr. King said, are very different from their wild ancestors. Their greatly increased productivity demands high standards of nutrition and management and protection from bad weather. Whereas the importance of nutrition and genetics is well recognized, the influence of environmental factors on disease incidence is not given the attention it deserves. A recent study by Withers of calf losses showed that the increased mortality in the early spring is greatest in the northern half of Britain and is probably due to the adverse effects of extreme cold, wide temperature ranges, and absence of sunshine. Phillips, from a study of knackery records in West Wales, showed a great increase in cows slaughtered during April each year, which is probably a reflexion of the adverse effects of confinement indoors on an inadequate diet during the winter months. Stock require to become acclimatized to colder and more rigorous conditions, which is why farmers prefer to "go north" for stock replacements. Mr. King gave a number of illustrations of the adverse effects of sudden changes of environment on farm stock, particularly in relation to their fertility. Pigs are particularly susceptible to a cold and damp environment, and the cost of providing heat for very young pigs is well repaid by a higher survival-rate and better growth. Cattle can with advantage be given more fresh air and exercise than the conventional cowshed or stall provides. The use of covered or semi-covered yards for cattle and of open-fronted sheds for calves favours the production of healthy stock.

Ventilation of animal buildings means providing sufficient fresh air without draughts and a reasonable temperature without high humidity. Mr. King pointed out the advantages of the Belfast type of piggery, for fattening pigs, with low well-insulated sleeping quarters and yards for water and excreta which are separated from the sleeping pens by concrete baffle walls and swing doors. Such houses provide a very even temperature throughout day and night, with a maximum variation of some $12^{\circ} \mathrm{F}$. With poultry kept under the intensive system, faulty ventilation is the chief error.

Mr. King concluded by advocating special attention to housing and feeding during the winter months in order to avoid the loss of condition which is so common during this period of the year.

In the discussion, Prof. J. G. Wright (University of Liverpool) mentioned the serious losses which result from cattle eating pieces of metal, such as baling wire, nails or screws. Losses from this cause are preventable. Some indication of the wide variety of such objects and the effects they produce were provided on the following day when members of the section visited the Veterinary Field Station of the University of Liverpool.
E. G. White 